\title{
The coherence of enactivism and mathematics education research: A case study
}

\author{
David A Reid \\ University of Bremen \\ dreid[]math.uni-bremen.de \\ Received December 2013; accepted August 2014; published Autumn 2014.
}

\begin{abstract}
This article addresses the question of the coherence of enactivism as a research perspective by making a case study of enactivism in mathematics education research. Main theoretical directions in mathematics education are reviewed and the history of adoption of concepts from enactivism is described. It is concluded that enactivism offers a 'grand theory' that can be brought to bear on most of the phenomena of interest in mathematics education research, and so it provides a sufficient theoretical framework. It has particular strength in describing interactions between cognitive systems, including human beings, human conversations and larger human social systems. Some apparent incoherencies of enactivism in mathematics education and in other fields come from the adoption of parts of enactivism that are then grafted onto incompatible theories. However, another significant source of incoherence is the inadequacy of Maturana's definition of a social system and the lack of a generally agreed upon alternative.
\end{abstract}

Keywords: enactivism; biology of cognition; mathematics education; theories of learning; autopoiesis; cognitive systems; social systems.

\section{Introduction}

Is enactivism a coherent and promising research perspective? Is it a conception, or maybe a framework for research? What is its future? In this article I will address these questions by making a case study of enactivism in my field, which is mathematics education research. I will review the main theoretical directions in mathematics education and the history of adoption of concepts from enactivism. I will consider whether enactivism provides a sufficient theoretical framework for research in mathematics education and whether enactivism is coherent in general. 


\section{What is Enactivism?}

Enactivism exists in the eyes of observers, and so any discussion of it must begin with a description of the authors' observations. For me enactivism is fundamentally a theory about autopoietic systems and the biology of cognition. My first encounter with it was Tree of Knowledge (Maturana \& Varela 1987) and I read backwards and forwards from there. Maturana's writing has been more significant to me than Varela's, especially 'Everything said is said by an observer' (Maturana 1987) and 'Reality: The search for objectivity or the quest for a compelling argument' (Maturana 1988). Hence, when I write about enactivism I am thinking of the ideas of Maturana and Varela up to and including Tree of Knowledge, plus material from The Embodied Mind (Varela, Thompson \& Rosch 1991) and later writing as far as it overlaps with Varela's prior work with Maturana. There are clearly many connections between enactivism and the work of Bateson, McCullogh, von Foerster and Lakoff, for example, but I do not see their work as defining enactivism itself.

I realise this reading of enactivism will only overlap and not coincide with that of many readers. After all, the words 'enaction' and 'enactive' were used first by Varela, Thompson and Rosch (1991) and Maturana never uses them, so my emphasis on Maturana's ideas may seem odd. And I am also paying little attention to Varela's later elaborations of enaction and the connections he makes to the phenomenology of Merleau-Ponty and Buddhist mindfulness/awareness practice. On the other hand, the description of ena-ction in The Embodied Mind depends on a number of concepts, such as embodiment, perceptually guided action, recurrent sensorimotor patterns, structure determinism and operational closure, that were developed during Varela's work with Maturana in the early 1970s, and first described in many joint and individual publications, most notably Autopoiesis and Cognition (Maturana and Varela 1980a) and Tree of Knowledge. And most importantly, the key isight of enactivism, it seems to me, is the founding of cognition in biology, and that insight is best reflected in the collaborative work of Maturana and Varela and Maturana's work since then.

\section{Theoretical frameworks in mathematics education}

Enactivism was introduced into mathematics education at a time when the main theoretical debate concerned how to describe the social interactions between individuals.

Two general theoretical positions on the relationship between social processes and psychological development can be identified in the current literature. These positions frequently appear to be in direct opposition in that one gives priority 
to social and cultural processes, and the other to the individual autonomous learner. (Cobb \& Bauersfeld 1995: 3)

Psychological theories, giving priority to the individual autonomous learner, entered mathematics education at its very beginning as an academic field. Sociocultural theories came much later, and their introduction created significant tension.

Mathematicians had taught mathematics and written mathematics textbooks for millennia before mathematics education emerged as an academic discipline. A possible marker of its origin is the first issue of the journal L'Enseignement Mathématique in 1899, which included both an article on mathematics teaching by the famous mathematician Henri Poincaré, as well an article on "scientific pedagogy" by Alfred Binet, the director of the Laboratory of Experimental Psychology at the Sorbonne (Kilpatrick 1992: 7). This bringing together of mathematics and psychology established the theoretical basis for the field of mathematics education.

After its birth as an academic field at the beginning of the twentieth century, the further development of mathematics education was disrupted by the interruption of international collaborations caused by the two world wars. After the post war recovery, the field was revitalised by the introduction of the genetic epistemology of the psychologist Jean Piaget (1896-1980, a student of Binet). This became the dominant theoretical framework for the rest of the century. The founding fathers of mathematics education from this time, Zoltan Dienes (1916-2014), Ephraim Fischbein (1920-1998), Caleb Gattegno (19111988) and Richard Skemp (1919-1995) all trained as both mathematics and psychologists, except Gattegno who collaborated directly with Piaget. The importance of psychology in mathematics education is also marked by the founding in 1976 of the International Group for the Psychology of Mathematics Education, whose annual conference became the main research conference in the field.

Even at this time, however, there was a recognition that mathematics education must also consider the contexts in which learning takes place. Heinrich Bauersfeld recalls:

From the very beginning [of PME] I was unhappy with the exclusive concentration on Psychology only, which meant focusing on the individual and neglecting the social dimensions of the complex teaching-learning processes. Research on the complex problems of learning/teaching-processes and of teaching teachers to teach mathematics will not arrive at helpful constructive information as long as such vast domains as language, human interaction (not the usual psychological interaction of variables!) and rich case studies are neglected and/or treated by inadequate research methods. (Nicol et al. 2008).

By the 1980s "Researchers were taking the social and cultural dimensions of mathematics education more seriously (Kilpatrick 1992: 30). This meant that 
the theories of psychology had to be supplemented both by teachers' experiences and by theories from other disciplines. "Practitioners were increasingly becoming members of the interdisciplinary groups needed to help research link the complexity of practice to theoretical constructs. The techniques and concepts used by anthropologists, sociologists, linguists and philosophers proved helpful in that task" (Kilpatrick 1992: 31).

However, as I will discuss below, sociocultural theories did not fit easily into a field dominated by psychological perspectives, and as indicated in the Cobb and Bauersfeld quotation above, the two approaches often seemed to be opposed. Researchers in both camps critiqued the perceived failings of theories used by the others. This was the context in which concepts from enactivism first entered mathematics education.

\section{Enactivist ideas in mathematics education}

In mathematics education the growing influence of enactivist ideas can be traced historically through references to the work of Maturana and Varela. Enactivist ideas have been introduced into mathematics education four times. The first references come from radical constructivists who sought to incorporate the concept of consensual domains in order to address criticisms that radical constructivism did not address learning in social situations. Tom Kieren's work then introduced the full range of enactivist concepts, and he was the first to use the work 'enactivist' to describe his research. At about the same time, the concept of embodied cognition began to be used by a number of other researchers with interests in bodily metaphors and gestures in mathematics. Finally, the concept of autopoiesis, as reframed by Niklas Luhmann, has been used by Heinz Steinbring to describe interactions in mathematics classrooms.

\section{Radical constructivism and consensual domains}

The first influence of enactivism (prior to the coining of the term) came from an attempt to integrate social elements into the radical constructivism of Ernst von Glasersfeld. In the late 1980s, Paul Cobb (a graduate student of von Glasersfeld's collaborator Les Steffe) began to refer to Maturana's concept of consensual domain (1980b, 1978a) in order to describe a world view or belief system shared by many individuals (see e.g., Cobb 1985, 1986). Von Glasersfeld (1989) himself also refers to Maturana (1980a) to account for the possibility of communication between individuals, which arises "in the course of protracted interaction, through mutual orientation and adaptation" (Glasersfeld 1989: 132). This led to Maturana's work being seen as a part or a type of radical constructivism. For example, Konold \& Johnson refer to "the radical construc- 
tivism of Maturana and von Glasersfeld” (1991: 10) and Krainer includes Maturana on a list of those putting forth "constructivist positions" along with Piaget and von Glasersfeld (1993: 69).

Critics often claimed that radical constructivism was unable to explain social phenomena (Ernest 2010: 41), and Maturana's concepts of consensual domain, domain of interpretation, isomorphic structures and mutual adaptation continue to be used by radical constructivists to address this criticism (e.g.,Thompson 2008). However, though von Glasersfeld and Maturana were friends, they disagreed on some fundamental points, such as structure determinism and the system's environment (Glasersfeld 1991, Kenny 2007). The radical constructivists, thought they were the first to apply Maturana's ideas in mathematics education, cannot be said to be using enactivism, as they pick and choose concepts, seeking those that give radical constructivism a language to describe social phenomena.

\section{Tom Kieren}

Tom Kieren has been described as "one of a very few pioneers of enactivism within the mathematics education community” (Kieren \& Simmt 2009: 28). In the mid 1980s he picked up Autopoiesis and Cognition (Maturana \& Varela 1980) and was strongly influenced by what he read. He also encountered enactivist concepts through a paper Maturana delivered with Karl Tomm at a conference of the Department of Psychiatry at the University of Calgary, on "Languaging and the emotion flow" in 1986 and through Tree of Knowledge (Maturana \& Varela 1987). Kieren was already well acquainted with radical constructivism, but found something new and exciting in Maturana's ideas. In 1988 he discussed this work with his colleague Susan Pirie and this led to the first publication in mathematics education that makes extensive use of Maturana's ideas, Pirie and Kieren (1989). They use the concepts of recursion in knowing, knowing as effective action as seen by an observer, autopoiesis, consensual coordination of action, and the aphorism "everything said is said by an observer" as the basis for a theory of mathematical understanding that has come to be known as the Pirie-Kieren model.

In 1994 Kieren published a reaction to two papers by radical constructivists in the Journal of Research in Childhood Education. In it he uses the word "enactivist" for the first time in the mathematics education literature; the word was coined in The Embodied Mind (Varela, Thompson \& Rosch 1991). Kieren (1994) describes enactivism as a position on cognition that includes the concepts of structure determinism, structural coupling, bringing forth a world, observer dependence, satisficing, and co-emergence.

In the 1990s Kieren supervised a number of graduate students who went on to use enactivist ideas in their work. These include Judy Barnes, Brent Davis, 
Lynn Gordon Calvert, Elaine Simmt, and myself. Almost all include in their doctoral dissertations extensive descriptions of enactivist ideas (Barnes 1994; Davis 1994; Gordon Calvert 1999; Reid 1995; Simmt 2000).

Of these graduate students, Davis has published the most extensively and has done much to spread enactivist ideas to the mathematics education community. His doctoral dissertation (1994) was the basis for his first book (1996), in which enactivist ideas are presented in detail. He places special emphasis on enactivism's denial of the mind/body split, and the entity/environment split (1996: 77). He also refers to autopoiesis, co-emergence, embodied cognition, double embodiment, knowing as being and doing, and structure-determinism. Davis also published several related journal articles (Davis 1995, 1997; Davis, Sumara \& Kieren 1996) in which he provides descriptions of enactivism as an interpretive framework. For mathematics education researchers such as Begg (1999, 2002, 2013) and Samson and Schafer $(2010,2011,2012)$, Davis is a primary reference for enactivist theory. However, Davis himself later came to regard enactivism as a variety of complexity science, and changed his focus to applications of complexity science in general to educational research (see, e.g., Davis 2004, Davis \& Sumara 2006).

Three other doctoral students, Elaine Simmt, Lynn Gordon Calvert, and myself, along with Kieren constituted the Enactivist Research Group at the University of Alberta. Together we presented enactivism informed interpretations of shared data from four perspectives (Gordon Calvert, Kieren, Reid \& Simmt 1995; Kieren, Gordon Calvert, Reid \& Simmt 1995; Kieren, Simmt, Gordon Calvert, \& Reid 1996). Key concepts used in those presentations were coemergence, structural determinism, autopoiesis, and double embodiment, and enactivism provided not only the interpretative frame but also the methodology.

Both Simmt and Gordon Calvert became professors at the University of Alberta, and doctoral work with an enactivist framework continues to be done there. The research of Joyce Mgombelo, Immaculate Namukasa, Jerome Proulx and Martina Metz at the University of Alberta has continued the enactivist tradition begun by Tom Kieren.

\section{The Bristol School}

After completing my dissertation (Reid 1995) I continued to make use of a wide range of enactivist ideas, especially Maturana's (1988) concept of an emotional orientation, in my research on the development of students' reasoning towards mathematical proof (see, e.g., Blackmore, Cluett, \& Reid 1996, Reid 1996, 1999, 2002ab; Reid \& Drodge 2000). Enactivism continues to 
provide the methodological underpinnings of my research into teachers' pedagogies (see http://www.acadiau.ca/ dreid/OT/).

In 1995 I met Laurinda Brown in a PME discussion group organised by Rafael Núñez and Laurie Edwards (see below). Brown had been using the work of Gregory Bateson (1972, 1979) extensively but had not discovered Maturana and Varela. I had not yet read Bateson's work. After exchanging reading lists, we began a long collaboration. With our colleagues Vicki Zack and Alf Coles we made use of enactivism as a theoretical framework, and also incorporated Bateson's work and later the work of Antonio Damasio (1994). His somatic marker hypothesis provided us with a neurological explanation for phenomena described by Maturana and Bateson (see, e.g., Brown \& Reid 2002, 2003, 2004, 2006; Brown, Reid \& Coles 2003; Reid \& Brown 1999; Reid, Brown, \& Coles 2001).

Brown introduced a number of graduate students to enactivist ideas, and two in particular picked them up and used them extensively. Maria Lozano completed her dissertation in 2004. She examined algebraic learning in the transition from arithmetic to algebra, using enactivism as both her methodology and theoretical framework (Lozano 2004). Alf Coles collaborated with Brown over many years, on research and publications (e.g., Brown and Coles 1997, 2000, 2008, 2010) that "adopted an enactivist epistemology and methodology" (Coles 2011: 18). In his doctoral dissertation (Coles 2011) he examined the patterns of communication in classrooms and teacher meetings from an explicitly enactivist perspective.

\section{Embodied mathematics}

The year 1995 can be seen as the birth year of another important theoretical framework in mathematics education, closely related but not identical to enactivism. In that year Stephen Campbell and A. J. Dawson published a paper on 'Learning as Embodied Action' (Campbell \& Dawson 1995) which draws strongly on The Embodied Mind (Varela, Thompson \& Rosch 1991). Rafael Núñez and Laurie Edwards in the same year presented a paper (Edwards \& Núñez 1995) and organised a discussion group at PME on non-objectivist cognitive science (Núñez \& Edwards 1995), drawing heavily on The Embodied Mind as well as the work of Lakoff (1987) and Johnson (1987) on body based metaphors in cognition. Since then embodied mathematics has emerged as a significant theoretical frame in mathematics education. It posits that all human cognition is embodied, that is "every subjective sensation, memory, thought, and emotion-anything at all that any human being can ever experience-is in principle enacted in some objective, observable, way as embodied behaviour." (Campbell 2010: 313). Three threads can be discerned within the theoretical framework of embodied mathematics. 
One thread, which Campbell (2010) calls 'mathematics educational neuroscience', seeks to investigate mathematics learning using neuroscientific tools such as eye-tracking and brain scans. In this thread the ideas of Varela serve chiefly as a starting point to justify examining cognition in terms of observable bodily changes.

A second thread builds chiefly on the work of Lakoff. A basic text is Where mathematics comes from: How the embodied mind brings mathematics into being (Lakoff \& Núñez 2000) in which they argue that mathematical concepts, even quite abstract concepts, are always based on bodily experiences, through metaphors. Researchers (e.g., Ferrara 2003; Oehrtman 2003) study the metaphors involved in students' understandings of mathematical concepts such as functions, limits, and sets. No reference is made to the work of Varela, except indirectly through references to publications of Edwards and Núñez.

A third thread focusses on the use of gestures in mathematics education. This thread can be represented by a special issue of the journal Educational Studies in Mathematics, (Radford, Edwards \& Arzarello 2009) in which embodied mathematics is used in combination with semiotics to research the role of gestures in mathematical thinking and communication. In this work Varela's ideas play a limited role, acting mainly as a reference for the concept of embodied cognition.

As noted above, the theoretical framework of embodied mathematics is related to enactivism, but distinct from it. The Embodied Mind (Varela, Thompson \& Rosch 1991) is a key reference for this school of research, but other work by Varela is rarely cited, and work by Maturana is almost never cited by researchers in the area.

\section{Autopoietic social systems}

The enactivist idea of autopoiesis found its way into mathematics education through one other channel, the sociological work of Nicholas Luhmann, which was applied to mathematics education by Heinz Steinbring. Luhmann (1986, 1995, 1997) considers social communication to be an example of an autopoietic system. In order to do so he generalises Maturana's concept of autopoiesis to apply to non-living systems that also have the properties of being self-organising and operationally closed. Within this broader conception of autopoietic systems he identifies three types: living systems, psychic systems and social systems. The elements of psychic and social systems are not physical but based on meaning, in consciousness and communication respectively. 
The relationship between psychic conscious mental and social communication systems is an important theme in Luhmann's work, and in its application to mathematics education.

Communication systems and mental systems (or consciousness) form two clearly separated autopoietic domains.... These two kinds of systems are, however, closely connected to each other in a particular tight relation and mutually form a 'portion of a necessary environment': Without the participation of consciousness systems there is no communication, and without the participation in communication, there is no development of the consciousness. (Baraldi et al. 1997: 86, translated by Steinbring 2005:320)

Steinbring uses Luhmann's concept autopoietic social systems composed of communications to analyse episodes in mathematics teaching (see, e.g., 1999, 2005). This approach has had only a limited influence in mathematics education.

\section{Summing up}

Enactivism has become recognised as a theoretical framework used in mathematics education, and it is interesting to see how it has been summarised by overviews of theories in the field.

Mason and Johnston-Wilder include enactivism in the Fundamental Constructs in Mathematics Education (2004). Key concepts cited are 'action is knowledge and knowledge is action" and 'everything said is said by an observer.' The enactivist idea of 'bringing forth a world' is seen as "entirely compatible with von Glasersfeld's radical constructivism” (Mason \& Johnston-Wilder 2004: 71), and radical constructivists such as Cobb, Yackel and Wood are described as having "taken up the enactivist view" (Mason \& Johnston-Wilder 2004: 72). The work of Campbell and Dawson (1995) is cited a particular example of the enactivist approach, with the idea of stressing and ignoring being presented as central. Much of Mason and Johnston-Wilder's summary seems to have been based on Campbell and Dawson's article, which appeared in a book edited by Mason. The body of work inspired by Tom Kieren is represented by a brief quotation from Davis, Sumara and Kieren (1996) which is seen as exemplary of "radical enactivism" (Mason \& Johnston-Wilder 2004: 73), in which learning and action are identified.

In the recent collection Theories of Mathematics Education (Sriraman \& English 2010) Paul Ernest contrasts four "philosophies of learning”: 'simple' constructivism, radical constructivism, enactivism and social constructivism. Ernest (2010) cites The Embodied Mind (Varela, Thompson \& Rosch 1991) as the original influence that brought enactivism into mathematics education and he lists autopoiesis and cognition-as-enaction as key concepts. He cites Lakoff and Johnson's work, as transmitted by Lakoff and Núñez, as a "source of 
enactivism" (Ernest 2010: 42). Ernest sees enactivism as "not so very different from Piaget's epistemology and learning theory and the radical constructivism to which it gave birth" (2010: 42). What Ernest sees are distinct in enactivism is the role of metaphor contributed by Lakoff. This suggests that it is the embodied mathematics research that has been Ernest's main source of information about enactivism. Another clue to this is his comment "What both enactivism and radical constructivism appear to share is the subordination of the social or the interpersonal dimension” (2010: 43).

\section{Mathematics: Mind or Society?}

Recall that when enactivist ideas were first introduced into mathematics education a fundamental tension existed between psychological theories or sociocultural theories. This tension was addressed in mathematics education in a number of ways.

As noted above, radical constructivists borrowed Maturana's concept of consensual domain in order to be able to address social aspects of learning. The concept of consensual domain was only referred to, however, and the full implications of incorporating the concept into radical constructivism were never, as far as I know, worked out. Given the fundamental ontological differences between radical constructivism and enactivism, it may not be possible to truly integrate the concept of consensual domain into radical constructivism. Adopting the concept of consensual domains without adopting the ontological basis for their existence would give rise to an incoherence in radical constructivism. This can only be resolved by either adopting Maturana's position on reality (effectively changing radical constructivism into enactivism) or by dropping the concept of consensual domains, leaving radical constructivism again open to the critique that it does not address learning in social contexts.

Cobb and Bauersfeld (1995) take a different approach, of employing both a radical constructivist framework as well the interactionist perspective developed by Bauersfeld (1980).

We arrived at the conclusion that psychological and sociological perspectives each tell half of a good story. What was needed was a combined approach that takes individual students' mathematical interpretations seriously while simultaneously seeing their activity as necessarily socially situated. (Cobb \& Bauersfeld 1995 p. ix)

They "seek to transcend the apparent opposition between collectivism and individualism by coordinating sociological analyses of the microculture established by the classroom community with cognitive analyses of individual students' constructive activities” (Cobb \& Bauersfeld 1995: 7). However, they are explicit that "this coordination does not ... produce a seamless theoretical 
framework" (Cobb \& Bauersfeld 1995: 8). It is a coordination of approaches, not a single combined approach.

Instead, the resulting orientation is analogous to Heisenberg's uncertainty principle. When the focus is on the individual, the social fades into the background, and vice versa. Further the emphasis given to one perspective or the other depends on the issues and purposes at hand. Thus ... there is no simple unification of the perspectives. (Cobb \& Bauersfeld 1995: 8)

Another approach begins with a sociocultural perspective and attempts to integrate psychological elements. The main example of this approach is social constructivism, which built on the work of the Belorussian psychologist Vygotsky. Partly out of a genuine interest in how thinking is related to language and society, and partly because the political and intellectual context of the Soviet Union in the 1930s demanded a Marxist element in any theory, Vygotsky developed a theory that pays explicit attention to how social and cultural patterns of interaction shape thinking. Beginning in the 1970s Vygotsky's ideas were adopted in mathematics education as an alternative, called social constructivism, to Piagetian constructivism.

Social constructivism, however, was critiqued as downplaying psychological processes in learning. This lead to efforts to create a more robust theory by adding psychological elements from Piagetian constructivism into the sociocultural theories of Vygotsky. As an example, Confrey (1992) relates how Wertsch (1985) "proposes that Piaget should be added into the Vygotskian program" (Confrey 1992: 13) both in the description of "natural" development and in the process of construction of scientific concepts. This, Confrey notes, results "in major changes and contradictions in Vygotsky's program" (1992: 13). This she sees as a general problem with any effort to integrate radical constructivist and sociocultural approaches by simple modifications of each theory.

These shifts of attention to include social interaction and cultural influence [in radical constructivism] imply deep reconceptualization of theory and methodology. An integrated theory will need to seek to reshape both theories to allow for both intra-cognitive and inter-cognitive activity. (Confrey 1992: 28)

Instead, Confrey proposes that an alternative theory is needed, and she lists a number of possible characteristics of such a theory. In the published version of her text, she does not go further than presenting her list. Intriguingly, however, Lerman (1996) in summarising her paper, claims she "argues for a new approach that incorporates Maturana and Varela's (1986) theory of autopoiesis" (Lerman 1996:141). It may be that she argued this when the paper was presented but not in the printed version.

Later, enactivist researchers in mathematics education elaborated the ways in which enactivism in fact offers a new approach that addresses both the individual and the social. 
In sum, then, cognition does not occur in minds and brains, but in the possibility for (shared) action. Enactivism thus embraces the insights of constructivism, but does not privilege the individual as the truth-determining authority. Similarly, enactivists are able to appreciate the social constructivist's concern for the transcendent (i.e., beyond the individual) nature of knowledge, but do not frame collective knowledge in opposition to subjective knowing. Truth and collective knowledge, for the enactivist, exist and consist in the possibility for joint or shared action-and that, necessarily, is larger than the solitary cognizing agent. Enactivism thus offers a way of bringing these discourses into conversation; for example, constructivism's subject and social constructivism's collective are regarded as self-similar forms. (Davis 1996:192-193)

While the debates between those taking psychological approaches and those taking sociocultural approaches have largely died down, this is not due to the adoption of enactivism as an alternative theory, as (perhaps) proposed by Confrey. Rather, most mathematics educators have adopted something like the eclectic approach of Cobb and Bauersfeld, using elements of sociocultural and constructivist theories without being too concerned about contradictions and coherence.

It might be asked why enactivism has not been more widely adopted, if it does offer a way to address both the individual and the social in mathematics education. The difficult writing style of Maturana may be a factor, as might be the range of alternative conceptions of enactivism offered by others (e.g., Di Paolo, Rohde and De Jaegher 2010). No one has yet managed to capture the full complexity of enactivism as a biological theory of cognition in language that is more accessible than Maturana's. The confusion around autopoiesis and social systems (explored below) may also be a factor. Many researchers in mathematics education would like to be able to use a common frame to describe cognition in living systems and social systems, and this has resulted in a number of approaches being taken that build on enactivist ideas while not treating enactivism as the full framework desired. Examples include Steinbring's adoption of Luhmann's version of autopoiesis, and Davis' embracing of complexity theory, which is more obviously applicable to complex dynamic systems of any order.

\section{Is enactivism in mathematics education sufficient?}

Within mathematics education the critiques of enactivism, and theoretical frameworks in general, have more often been about their sufficiency to address the phenomena of interest to mathematics educators than about their internal consistency. However, the two issues are related. As Confrey's comments above indicate there is a concern that any theory that is sufficient to address both individual learning and social interactions will be incoherent. In this section I will focus on the question of whether enactivism is sufficient 
within mathematics education, and this discussion will set the stage for a consideration of whether enactivism is coherent.

First it will be necessary to consider the nature of theories in mathematics education from two perspectives. Theories in mathematics education are examples of what Bernstein (2000) calls "horizontal knowledge structures" and they occur both as "grand" theories and as local theories. This establishes the context for the acceptance of enactivism as a theory and its limits when applied to mathematics education. I will then address critiques from within mathematics education concerning the sufficiency of enactivism in describing social systems.

\section{The knowledge structure of mathematics education}

As Lerman (2000) points out, education has what Bernstein (2000) calls a "horizontal knowledge structure." This means that new theories in education tend to establish new research domains with their own language. They don't replace other domains, as occurs in vertical knowledge structures like physics, where heliocentrism replaced geocentrism rather than establishing a new research domain alongside it. In mathematics education a new theory like embodied mathematics is not expected to replace other theories, taking over their research domains and transforming them, but rather to establish a new research domain. While proponents of any particular theory would like to think that their theory has the potential to replace others, due to the horizontality of the knowledge structure this does not normally occur.

Furthermore, education in general has a weak grammar; its theories are not able to produce unambiguous descriptions of phenomena. Objects of study in education, such as cognition, learning. knowledge, and emotion, cannot be defined in the way objects of study in physics can be. They are instead described within the frame of reference of a theory. In order to learn what "cognition" means in radical constructivism or embodied cognition "one needs to learn the language of radical constructivism or embodied cognition" (Lerman 2000: 101).

Lerman claims that theories in mathematics education are incommensurable, in principle.

Where a constructivist might interpret a classroom transcript in terms of the possible knowledge construction of the individual participants, viewing the researcher's account as itself a construction (Steffe and Thompson 2000), someone using socio-cultural theory might draw on notions of a zone of proximal development. Constructivists might find that describing learning as an induction into mathematics, as taking on board concepts that are on the intersubjective plane, incoherent in terms of the theory they are using (and 
a similar description of the reverse can of course be given). In this sense, these parallel discourses are incommensurable. (Lerman 2010: 102)

\section{Grand and local theories}

In mathematics education empirical research always takes place with two kinds of theories in play, grand theories and local or intermediate theories, frameworks and models (Ruthven, Laborde, Leach \& Tiberghien 2009).

"Grand theories" [are] theories general in scope and correspondingly abstract in form; notably theories of human development and learning, of the epistemology of the discipline, or of the process of instruction. (Ruthven, Laborde, Leach \& Tiberghien 2009: 330)

Grand theories apply not only within mathematics education but to a much wider domain, and within mathematics education a grand theory is expected to address all phenomena of interest. Radical constructivism, sociocultural theory and enactivism are examples of grand theories (Simon 2013). They are expected to be useful in describing any phenomenon of interest in mathematics teaching and learning, either directly, or in some cases by providing a reasoned argument that the phenomenon in question does not exist. Transmission of knowledge is an example of a phenomenon that radical constructivism and enactivism would address by questioning and reframing rather than addressing directly.

Local theories, on the other hand, are applicable only within mathematics education, and usually only within a small domain of mathematics education. For example, a theory describing how the principles of arithmetic might be abstracted to become theorems of algebra would be a local theory.

If enactivism is a grand theory then it must address all phenomena of interest to mathematics educators. This includes individual learning, accounting for known phenomena such as the importance of physical materials in learning mathematics, the transition to abstract thinking, and the role of language. It also includes social interactions, including phenomena related to teacher student interactions, student student interactions, and interactions mediated by objects and symbols. Finally it includes the behaviours of social systems.

\section{Apparent insufficiencies of enactivism for mathematics education}

Enactivism has been critiqued as not dealing with social interactions, which are undoubtedly important phenomena in mathematics education. For example, Ernest (2010) comments: 
What both enactivism and radical constructivism appear to share is the subordination of the social or the interpersonal dimension, and indeed the existence of other persons to constructions and perceived regularities in the experienced environment. The knowers' own body might be a given, albeit emergent, but other persons' bodies and overall beings are not. Ironically, language, which is the primary seat of metaphor, is the quintessential social construction. But language, like other persons, seems to be removed and exterior to the primary sources of knowledge of the enactive self in these perspectives. (Ernest 2010: 43)

Ernest, however, seems to be referring not to enactivism, but to embodied mathematics. The claim that language and other persons are not central to enactivism is clearly wrong. In fact, recall that the first mathematics educators to use concepts from enactivism, radical constructivists, were interested precisely in ways to refer to social phenomena. This seems to have been forgotten. Perhaps this is a consequence of the way enactivist ideas have been adopted in mathematics education, usually as isolated concepts, grafted onto other theoretical frames. Radical constructivists have adopted the concept of a consensual domain, and the concept of embodied cognition has been employed by researchers interested in gesture, but neither group has actually adopted enactivism as a theoretical frame. This does not mean that enactivism itself is insufficient, however, only that the way it has been employed by radical constructivist and embodied mathematics researchers is insufficient.

\section{Social systems}

Ernest's critique above does point out that it is essential to address social aspects of learning in mathematics education. This must be done at two levels, the interpersonal and the social. The interpersonal level includes the social interactions and language use of teacher and students. The social level concerns the behaviour and function of social systems, such as schools, nations and cultures. While enactivism undeniably addresses the social interactions and language use of living systems, it could be critiqued as being unable to address the functioning of non-living social systems. Before responding to this critique it is worth recalling two approaches related to enactivism that have directly addressed social systems. Steinbring's use of Luhmann's sociological theory was described above. Here I will describe Davis's use of complexity theory.

Davis and colleagues (Davis \& Sumara 1997, 2006; Davis \& Simmt 2003) use complexity theory to extend enactivism to social systems, as well as other complex systems.

Enactivism understands the individual to be part of - that is, embedded in and a subsystem to-a series of increasingly complex systems with integrities of their own, including classroom groupings, schools, communities, cultures, humanity 
and the biosphere. The notion of "embodied knowledge" extends to bodies much larger than our own. (Davis 1996:193)

This approach extends the types of systems it can address, at the cost of treating them all as complex systems. Complex systems have many important properties, but far fewer than the living systems that enactivism focusses on. This limits the body of concepts that can be brought into the analysis of phenomena in mathematics education. It also risks extending concepts applicable to autopoietic systems, like embodiment, to complex systems in general, as is done in the quote above. There is no reason to believe that this can be done without diluting or destroying the concepts. "Using a concept outside its proper context of application means committing a double fault: the concept will work properly neither in the original nor the new domain" (Maturana \& Poerksen 2007: 70)

Enactivism has as its main focus living systems, and so it is much more restricted than complexity theory. However, there is no need to begin with the common properties of all complex systems in an effort to address social phenomena. Maturana himself showed how enactivism ideas can be extended to social systems, and more importantly which ideas can be extended to social systems. Maturana rejected the idea of extending ideas such as autopoiesis, that had been developed in relation to living systems, to social systems without first establishing what the characteristics of social systems are. Hence he begins a paper presented to a symposium on "the theory of autopoietic systems as a new foundation of the social sciences" (Maturana 1980b) by describing what he sees as the organisation of a social system:

I propose that a collection of interacting living systems that, in the realization of their autopoiesis through the actual operation of their properties as autopoietic unities, constitute a system that as a network of interactions and relations operates with respect to them as a medium in which they realize their autopoiesis while integrating it, is indistinguishable, from a natural social systems and is, in fact, one such system. (Maturana 1980b:12)

This definition of social organisation has not been adopted by mathematics educators and is only referred to briefly by a few radical constructivists. It is also problematic (see below) but it cannot be said that enactivism lacks a way to describe social systems.

Enactivism provides a grand theory that is sufficient to address both the individual and the social in mathematics education. It does so without juxtaposing incompatible frameworks or limiting itself to over general descriptions. But it will not become the dominant grand theory in mathematics education, simply because of the way theories become dominant in domains with horizontal knowledge structures. And there remain aspects of mathematics education that enactivism does not address, most notably the 
nature and growth of mathematics itself. Other theories must be used to address this aspect.

With the ability to address a wide range of phenomena with a single framework comes the risk of incoherence, and in the next section I will turn to the question of coherence, using my case study of mathematics education research to focus the discussion around the nature of autopoietic systems and social systems.

\section{Is Enactivism Coherent in General?}

My case study of enactivism in mathematics education suggests that a possible source of incoherencies is the description of systems using inappropriate terminology. There is a need to be able to describe social systems in particular, and because social systems are like living systems in some ways, there have been efforts to apply Maturana's and Varela's concepts to them. However, unless care is taken to establish the nature of social systems first, there is a danger of misapplying enactivist concepts. Maturana and Varela describe features of living systems, without usually indicating which of the features arise only because the systems are living, and which might apply also to nonliving systems. To clarify my discussion of these points I will begin by reviewing the properties of autopoietic systems, which are often given in an abbreviated form that makes it too easy to over generalise the concept. I will then propose a nesting of types of systems and locate living systems, cognitive systems and social systems in it. Through a discussion of the properties of these types of systems, I will locate possible sources of incoherence in enactivism and address them.

\section{Autopoietic systems}

It is helpful to be precise about how exactly Maturana and Varela characterise autopoietic systems. Autopoietic systems have a number of properties, all of which must be present for them to be autopoietic. These are the following.

A. Autopoietic systems are self-producing. They create their own components. "The relations that characterize autopoiesis are relations of productions of components" (Varela 1979: 54).

B. Autopoietic systems are embodied. They create a boundary between themselves and everything else. "It is a defining feature of an autopoietic system that it should specify its own boundaries" (Varela 1979: 54).

C. Autopoietic systems are self-organising. The processes or interactions between components are organised into a recursive network 
that (re)generates itself. "Autopoietic systems ... have their own organization as the critical fundamental variable that they actively maintain constant.” (Maturana 1975: 318)

D. Autopoietic systems are composite unities. They are distinguished both as entities and also as networks of interacting components.

E. Autopoietic systems are interactionally open. "Every system will maintain endless interactions with the environment which will impinge and perturb it. If this were not so, we could not even distinguish it." (Varela \& Goguen 1978: 294, original emphasis removed).

F. Autopoietic systems are mechanistic. Their "organization is specifiable only in terms of relations between processes generated by the interactions of components, and not by spatial relations between these components." (Varela, Maturana \& Uribe 1974: 188). Mechanistic systems are structure determined. "A structure determined system is a system such that all that takes place in it, or happens to it at any instant, is determined by its structure at that instant” (Maturana 2002:15).

Properties A and B distinguish autopoietic systems from other autonomous systems, and hence are especially important. However, they are not by themselves sufficient, and focussing on those two properties would mean ignoring important properties that autopoietic systems have in common with other self-organising systems.

Properties C and D together define organisational closure, the distinguishing property of autonomous systems.

An organizationally closed unity is defined as a composite unity by a network of interactions of components that (i) through their interactions recursively regenerate the network of interactions that produced them, and (ii) realize the network as a unity in the space in which the components exist by constituting and specifying the unity's boundaries as a cleavage from the background (Varela 1981:15)

The distinction between properties $\mathrm{A}$ and $\mathrm{B}$, and properties $\mathrm{C}$ and $\mathrm{D}$ is not always understood, and this results in the misapplication of the label 'autopoietic' to autonomous systems that are not autopoietic. "The distinction between autopoiesis as proper to the unitary character of living organisms in the physical space, and autonomy as a general phenomenon applicable in other spaces of interactions, has been consistently confused and left unclarified" (Varela 1981:14). Autonomous systems have properties C and D but not properties A and B. 
Property A (self-production) and property C (self-organisation) both concern the generative capacity of the network of interactions in the system. Selfproduction concerns the production of the system's components. Selforganisation concerns the creation and maintenance of the network of interactions between those components. Neither implies the other. Autocatalytic systems create their own components, and so they are selfproducing, but they do not maintain the organisation that allows them to do so, so they are not self-organising (Maturana \& Varela 1980: 94). Varela (1979) describes the immune system as an example of an autonomous system, i.e., a system with properties $C$ and D, but its components are produced outside the system so it is not autopoietic.

Property B (embodiment) and property D (unity) both concern the boundary between the system and its medium. However embodiment refers to the production by the system of its boundary which is made of components of the system, while unity refers to the way the system is perceived by an observer, as being both a unity as well as a network of interacting components. The immune system is seen as a system, as a unity, as well as being seen as composed of components that interact. But it does not produce a boundary in the space of its components, which are cells. "The immune system defines a boundary not in a topological sense, but rather in a space of molecular configurations, by specifying what shapes can enter into the ongoing interactions of the system at every point in time" (Varela 1981:18).

The boundary between the system and its medium is also related to property $\mathrm{E}$ (interactional openness). A boundary both marks the extent of a system, as well as providing the means by which it interacts with its medium. The importance of interactions between the system and its medium through its boundary is indicated by this recent definition of autopoiesis: "A system is autopoietic if: (a) it has a semi-permeable boundary, (b) the boundary is produced from within the system, and (c) it encompasses reactions that regenerate the components of the system.” (Varela 2000, in Bourgine \& Stewart 2004: 329). A system that did not interact with its medium would be unobservable, and in addition, would not last long as it would have no way to import energy to offset entropy.

Property F (mechanistic) places autopoietic systems among dynamic systems, which are defined by recursive properties rather than by geometric characteristics, which can also give rise to emergent properties (as is the case in crystals). This property is also a reminder that autopoiesis is a non-vitalist description of life. Being alive comes from recursive properties of the system rather than the presence of a vital spark or substance. 


\section{Nesting of types of systems}

Of the properties of autopoietic systems listed above, property E must be the most general. If a unity is not open to interactions with an observer, it cannot be observed. All the other properties can only apply to observable unities. This is because properties are not properties of the unity but properties of the observer's interactions with it.

The basic cognitive operation that we perform as observers is the operation of distinction. By means of this operation we specify a unity as an entity distinct from a background, characterize both unity and background with the properties with which this operation endows them, and specify their separability. (Maturana \& Varela 1980: xix)

Property D distinguishes composite unities from simple unities.

A unity thus specified [by an operation of distinction] is a simple unity that defines through its properties the space in which it exists and the phenomenal domain which it may generate in its interactions with other unities. If we recursively apply the operation of distinction to a unity, so that we distinguish components in it; we respecify it as a composite unity that exists in the space that its components define because it is through the specified properties of its components that we observers distinguish it. Yet we can always treat a composite unity as a simple unity that does not exist in the space of its components, but which exists in a space that it defines through the properties that characterize it as a simple unity. (Maturana \& Varela 1980: xix)

Some unities can only be observed as simple unities. Which unities are simple depends on the observer of course. In my case, given a sphere of clear crystal I observe it as a simple unity. Other observers say that the crystal ball has components, atoms in a particular configuration, but I do not observe those components, so it is a simple unity for me. Composite unities can be observed in two ways, either as a simple unity or as a set of components. Varela (1979) calls these two ways of observing the 'behavioural view' and the 'recursive view' respectively. Maturana and Varela use the word 'system' to refer only to composite unities observed recursively, which is a narrower usage than is common is systems theory generally, and which can lead to seeming incoherencies.

Property B can apply to both simple unities and composite unities. I observe the crystal ball as having a topological boundary between it and not-it. I can also observe through a microscope the topological boundary between a cell and its medium. Because the cell is a component entity, I can observe its boundary in two ways, either as an edge between it and not-it, or as a component of the cell itself.

Within composite unities we can distinguish between static unities and dynamic or mechanistic unities. A static unity is distinguished by the spatial relations between its components. As an observer I distinguish a table as 
a simple unity by the interactions I can have with it, and as a composite unity by the way its parts are put together. A dynamic or mechanistic unity is distinguished by the "relations between processes generated by the interactions of components" (Varela, Maturana \& Uribe 1974: 188). The spacial relations between the components of a mechanistic unity are not fixed, but its components interact in ways that define its organisation.

Finally, I discussed above autonomous systems and self-producing systems. These are overlapping subtypes of mechanistic systems. Autopoietic systems are located in the intersection of autonomous systems, self-producing systems and embodied unities (See Figure 1).

Figure 1: Nested types of systems

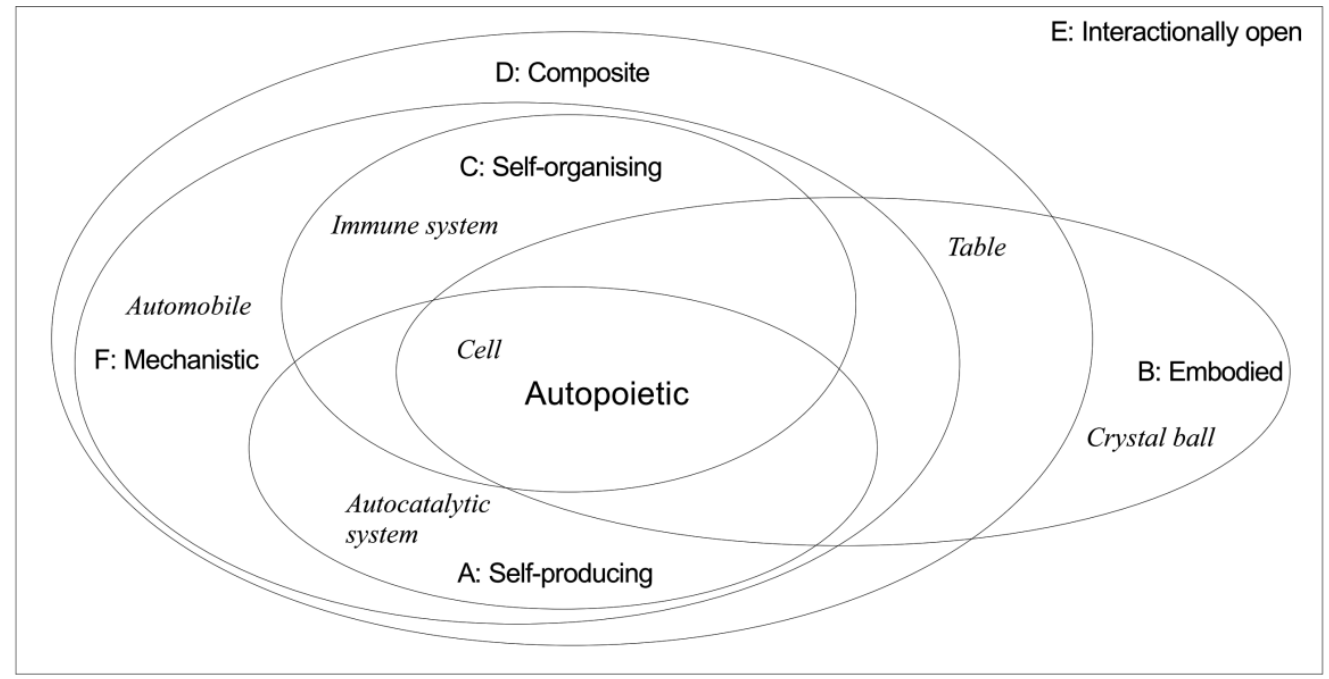

Having identified the key properties of autopoietic systems and having shown how they are nested, I will now turn to some specific systems of interest: living systems, cognitive systems and social systems, and discuss where they fit into the nesting of properties.

\section{Living systems}

A question that has been discussed a great length is whether or not the categories 'living system' and 'autopoietic system' are identical. Maturana and Varela initially coined the term 'autopoiesis' in order to characterise living systems, and claimed "autopoiesis is necessary and sufficient to characterize the organization of living systems" (1980:82). This suggests that all autopoietic systems are living systems and all living systems are autopoietic. However, as 
soon as the word was defined, it began to be applied to systems that are not usually thought of as living, including social systems. Maturana and Varela may have contributed to this confusion themselves by describing a computer model as autopoietic (Varela, Maturana \& Uribe 1974, Varela 1979).

If autopoiesis is not sufficient to characterise living systems, what else is required? Maturana clarifies "An autopoietic system that exists in physical space is a living system (or, more correctly, the physical space is the space that the components of living systems specify and in which they exist)" (1978a: 36). Computer models do not exist in physical space, and so are not alive. What exactly is physical space? "The physical space is defined by components that can be determined by operations that characterize them in terms of properties such as masses, forces, accelerations, distances, fields, etc." (Maturana \& Varela 1980: 112).

Another characterisation is that living systems are autopoietic systems whose components are molecules. In fact, this requirement of having molecular components came before the word 'autopoiesis' was coined.

At the beginning of the year 1964 I began to say that living systems were constituted as unities or discrete entities as circular closed dynamics of molecular productions open to the flow of molecules through them in which everything could change except their closed circular dynamics of molecular productions. (Maturana 2002: 8)

Maturana goes on to say "I also claim that autopoiesis occurs only in the molecular domain" (Maturana 2002: 8). At one point he did think it "possible that autopoietic systems could exist in domains different from the molecular one" (Maturana 2002: 14) however, he later came to see the molecular domain as having unique properties necessary for autopoiesis.

Molecules through their interactions give rise to molecules and dynamic systems of molecular productions, in diffuse and localized processes that constitute discrete entities. I think that due to this peculiarity of the molecular domain this is the only domain in which autopoietic systems can take place as discrete singular systems that operate through thermal agitation and dynamic architecture. (Maturana 2002: 8)

This seems to be a claim that could be empirically tested. In the cybernetic tradition, whether or not a system is autopoietic ought to be a matter of the system's organisation, independent of the nature of its components. "The actual nature of the components, and the particular properties that these may possess other than those participating in the interactions and transformations which constitute the system, are irrelevant and can be any" (Maturana \& Varela 1980: 77). This leaves open the possibility that there might be nonliving, non-molecular autopoietic systems. Of course, Maturana has every right to narrow the meaning of 'autopoiesis' to apply only to living, molecular systems, making autopoiesis a matter not only of organisation but also of the 
type of components involved. This would only mean that another word would be required to describe systems that have the same organisation as living, molecular systems, but are made of non-molecular components. While I sympathise with Maturana's fears that the concept of autopoiesis could become useless if it becomes ill defined or over-applied, there seems to me to be some value in describing living systems as molecular autopoietic systems, leaving open the possibility that autopoietic systems could be created from other components. I would agree with Varela:

The relations that characterize autopoiesis are relations of productions of components. ... Given this notion of production of components, it follows that the cases of autopoiesis we can actually exhibit, such as living systems or the example described in Varela et al. (1974), have as a criteria of distinction a topological boundary, and the processes that define them occur in a physicallike space, actual or simulated in a computer. (Varela 1981:15)

Computer models can be autopoietic in a "physical-like space." While Varela's original model has been critiqued (on the basis that it included a component, a catalyst, that it cannot produce, Bourgine \& Stewart 2004) efforts continue to produce computer models that have all the properties of an autopoietic system, within the space they define. In other words, I would argue that living systems are located entirely in the intersection of autonomous systems, selfproducing systems and embodied unities (see Figure 2) but that they do not fill it. There could be autopoietic systems that are non-living.

\section{Cognitive systems}

Enactivism is a theory of cognition, in which cognition is seen as a property of all living systems, which are defined as autopoietic systems.

A cognitive system is a system whose organization defines a domain of interactions in which it can act with relevance to the maintenance of itself, and the process of cognition is the actual (inductive) acting or behaving in the domain. Living systems are cognitive systems, and living as a process is a process of cognition. This statement is valid for all organisms, with and without a nervous system. (Maturana 1980a: 13).

Succinctly, cognition is "effective behavior in a medium" (Maturana 1978b: 37). What types of systems can behave effectively in a medium? Living systems certainly can, and it is the embedding of learning and cognition in a general study of life that makes enactivism distinctive. But living systems are not the only systems that define a domain of interactions in which they can act with relevance to the maintenance of themselves. All that is required is that the system engage in maintaining itself, and that true of autonomous systems in general. "The mechanisms of identity of an autonomous system correlate with the establishment of cognitive interactions with its environment" (Varela 1979: 211). Varela gives as two examples the nervous system and the immune 
system, but he also discusses cognitive social systems, including transient interactions like conversations.

Every autonomous structure will exhibit a cognitive domain and behave as a separate, distinct aggregate. Such autonomous units can be constituted by any processes capable of engaging in organizational closure. whether molecular interactions, managerial manipulations, or conversational participation.... I am saying, then, that whenever we engage in social interactions that we label as dialogue or conversation, these constitute autonomous aggregates, which exhibit all the properties of other autonomous units. (Varela 1979: 269)

This broadening of the meaning of cognition is useful in educational research, where a focus on organisms with nervous systems, especially people, can obscure fundamental issues such as the role of structural coupling in learning. Research on learning and cognition is not restricted to human learning and cognition, or even the cognition of living systems. Cognitive systems are located in and coincide with autonomous systems (see Figure 2).

Figure 2: Cognitive and living systems

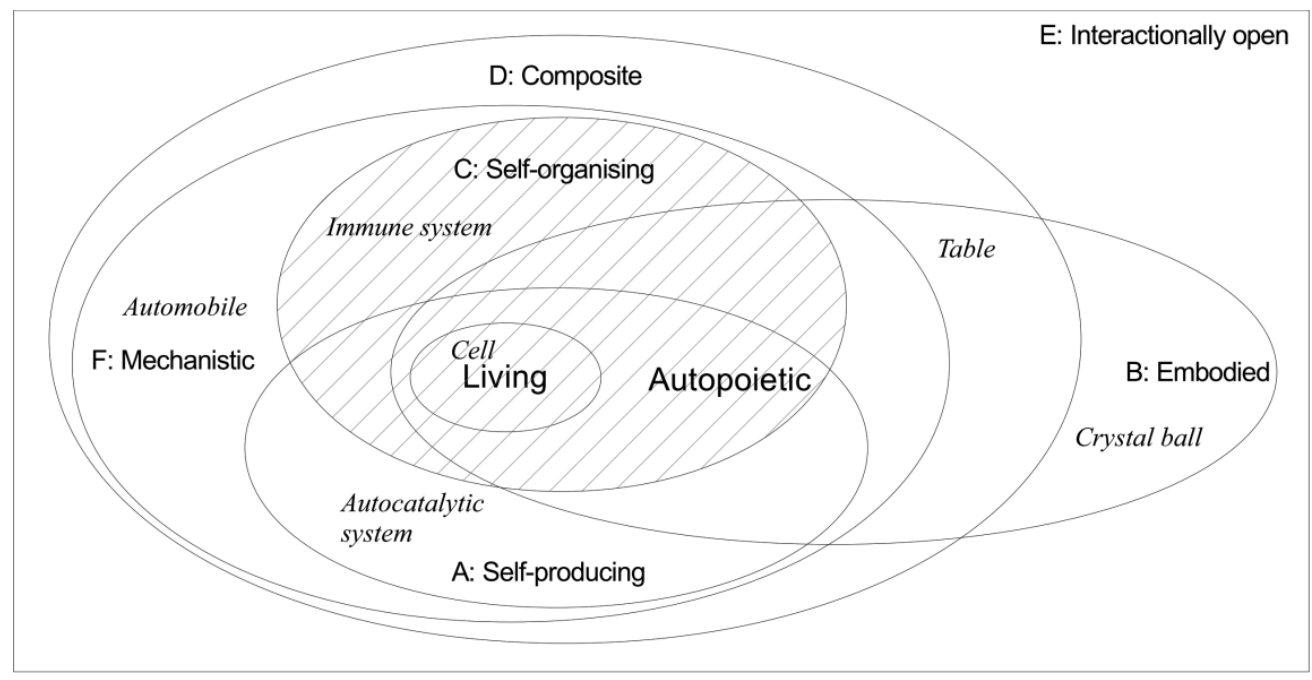

\section{Social systems}

If there is an area where enactivism is incoherent, it may well be in the treatment of social systems. This is perhaps not surprising, as Maturana and Varela specialised in the study of living systems, and their comments on social systems did not rest on the same level of expertise. In addition, if one assumes that the components of social systems are living systems, as they did, and therefore that the components of human social systems are human beings, then one is limited in the type of observations that are possible. 
Nothing prevents the observer himself from being part of the process of specifying the system, not only by describing it, but by being one link in the network of processes that defines the system. This situation is peculiar in that the describer cannot step outside of the unity to consider its boundaries and environment simultaneously, but it is associated with the unity's functioning always as a determining component. Such situations, to which most of the autonomous social systems belong, are characterized by a dynamics in which the very description of the system makes the system different. At each stage, the observer relates to the system through an understanding which modifies his relationship to the system. This is, properly speaking, the hermeneutic circle of interpretation-action, on which all human activity is based. (Varela 1981: 16)

Human beings observing human social systems are limited in two ways. First, they cannot take a behavioural view on the system, seeing it a simple unity, stepping "outside of the unity to consider its boundaries and environment". Human observers of human social systems are always components of the system or its environment and can only observe it with a recursive view, focussed on its components and the interactions between them. Second, describing a social system is a way of interacting with its components, in a way that describing a cell is not: "The very description of the system makes the system different.” Given these challenges it is not surprising that Maturana and Varela had some difficulties describing social systems.

However, there are some points about which they are clear and consistent. First, that integrating social systems into enactivism must begin by understanding social phenomena independently of enactivist concepts and terminology. Second, that the components of social systems are living systems. And third, that social systems are not autopoietic.

Maturana begins his 1980 essay 'Man and society' by asking "What is a social system?” (1980b: 11) and giving as the criterion for judging an answer to this question comparison to "the same phenomena that a natural social system appears to generate in its operation" (1980b: 11). In other words, before proposing an answer to the question "What is a social system?" it is necessary to observe social phenomena. Maturana saw this as a fundamental problem in Luhmann's use of the concept of autopoiesis.

I suggest that we start with the question of the characteristics of social phenomena. The concept of society historically precedes the idea of the autopoiesis of living systems. Society was the primary subject of debate; autopoiesis and social systems came much later. It follows, therefore, that we should first deal with all the relevant phenomena appearing in the analyses of society and only afterwards ask ourselves whether they may be elucidated more precisely in terms of the concept of autopoiesis. (Maturana \& Poerksen 2007: 70)

Another disagreement Maturana had with Luhmann concerned the components of social systems. Luhmann proposed that the components of a social system are communications and that human beings form a part of the 
medium in which the social system exists. Maturana rejected this position: "When we speak about social systems in our everyday life, however, we naturally have in mind all the individuals with their peculiar properties" (Maturana \& Poerksen 2007: 71). "A social system can only be integrated by living systems” (Maturana 1980: 13). Maturana's clearest definition of a social system starts with living systems:

[A social system is] a collection of interacting living systems that, in the realization of their autopoiesis through the actual operation of their properties as autopoietic unities, constitute a system that as a network of interactions and relations operates with respect to them as a medium in which they realize their autopoiesis while integrating it. (Maturana 1980b: 11-12)

Although Maturana and Varela could not agree completely on how to treat social systems (Maturana \& Varela 1980: xxiv), Varela also assumes that the components of human social systems are human beings, as indicated in his remark about autonomous social systems quoted above (Varela 1981: 16).

Both Maturana and Varela are clear that they do not see social systems as autopoietic. Social systems can be autonomous (i.e., they have properties C-F) but social systems do not have boundaries and do not produce their components.

There have been proposals suggesting that certain human systems, such as an institution, should be understood as autopoietic (Beer 1975; Zeleny and Pierre 1976). From what I have said I believe that these proposals are category mistakes: they confuse autopoiesis with autonomy. (Varela 1981: 15)

However, Maturana occasionally makes comments that makes this point less clear.

Just imagine for a moment a social system that is, in actual fact, functioning autopoietically. It would be an autopoietic system of the third order, itself composed of autopoietic systems of the second order. This would entail that every single process taking place within this system would necessarily be subservient to the maintenance of the autopoiesis of the whole. Consequently, the individuals with all their peculiarities and diverse forms of self-presentation would vanish. They would have to subordinate themselves to the maintenance of autopoiesis. Their fate is of no further relevance. They must conform in order to preserve the identity of the system. This kind of negation of the individual is among the characteristics of totalitarian systems. Stalin, therefore, forced party members who did not share his outlook to give up their positions so as not to endanger the cohesion and the unity of the party. In a democratic form of communal life, however, individuals are of central relevance and, in fact, indispensable. Their properties create the unique character of a social system. (Maturana \& Poerksen 2007: 72)

For Maturana, a social system is "a medium in which [living systems] realize their autopoiesis” (Maturana 1980b: 12), which means he must reject any system that interferes with the autopoiesis of the living systems in it. But as he 
notes, totalitarian systems do precisely this. By Maturana's definition, totalitarian systems are not social systems. "A social system that forbids and even principally excludes complaint and protest is not a social system. It is a system of tyranny.” (Maturana \& Poerksen 2007: 72). Given that Maturana developed his definition of a social system while in exile from Pinochet's Chile, he may have had reasons to characterise social systems in the way he did. However, it is not only totalitarian systems that are excluded by Maturana's definition.

A person who works for a given society and who cannot stop working for it without risking the loss of his autopoiesis because he has no other means of survival outside this work-relation, is under social abuse. Example: In a capitalistic economic system a worker is not a member of the productive society through which he earns his living and, therefore, only works for it. If, under these circumstances, there is no employment with respect to his abilities, and if he has no other independent means of survival, he is under social abuse. Such a person cannot enter into a work-agreement on terms generated by the fundamental equality that permits cooperation, and must surrender his autonomy as a human being in order to survive. (Maturana 1980b: 18)

Armies, police departments, fire departments and other organisations that subsume their members' autopoiesis to the goals of the organisation are also excluded by Maturana's definition of a social system. However, Maturana states that "In general any organism, and in particular any human being, can be simultaneously a member of many social systems, such as a family, a club, an army, a political party, a religion or a nation, and can operate in one or other without necessarily being in internal contradiction” (Maturana \& Varela 1980: xxviii). It is not at all clear that armies, religions and nations are systems that support the autopoiesis of their component human beings. And armies, religions and nations routinely restrict complaint and protest. Perhaps Maturana did not mean to include all religions and nations as social systems, but it is hard to imagine any army that would fit his definition of a social system.

A further aspect of Maturana's definition of a social system is the role of love in constituting a human social system.

What determines the constitution of a social system are the recurrent interactions of the same autopoietic systems. In other words, any biological stabilization of the structures of the interacting organisms that results in the recurrence of their interactions, may generate a social system. Among human beings the basic stabilizing factor in the constitution of a social system is the phenomenon of love, the seeing of the other as a partner in some or all the dimensions of living. (Maturana \& Varela 1980: xxvi)

It may be that Maturana has in mind an ideal human society, rather than any actual human society. 
A human society in which to see all human beings as equivalent to oneself, and to love them, is operationally legitimate without demanding from them a larger surrender of individuality and autonomy than the measure that one is willing to accept for oneself while integrating it as an observer, is a product of human art, that is, an artificial society that admits change and accepts every human being as not dispensable. (Maturana \& Varela 1980: xxix)

If we accept Maturana's definition of social system, then we require another word for those composite unities that most people consider to be social systems: families, clubs, armies, political parties, religions, nations, etc. Either that or we need another definition of 'social system' in enactivist terms. Because Maturana's definition of a social system is problematic, and was never accepted by Varela, enactivism lacks a coherent definition of 'social system' derived from primary sources. This has left the field open to many proposals of alternative definitions, from Beer (1980) to Zeleny (Zeleny \& Hufford 1991). This host of alternatives makes it impossible to place social systems definitively in the nesting of types of systems depicted in Figure 1. Social systems may or may not be autopoietic, but there seems to be a general agreement that they are at least autonomous, and so have many interesting properties.

\section{Conclusion}

To conclude I will reiterate a few of the main points I have made above. First, in mathematics education research enactivism offers a 'grand theory' that can be brought to bear on most of the phenomena of interest to mathematics educators. It has particular strength in describing interactions between cognitive systems, including human beings, human conversations and larger human social systems. Much remains to be done in exploring the potential of enactivism for social cognition. Second, some apparent incoherencies of enactivism come from the adoption, in mathematics education but also in other fields, of parts of enactivism which are then grafted onto incompatible theories. This opens up enactivism to critiques from both within mathematics education and outside the field. Most strongly, in my opinion, theories of cognition that claims to be enactivist, but rely only on the philosophical arguments introduced in The Embodied Mind rather than the biological arguments presented in Autopoiesis and Cognition, leave enactivism open to philosophical critiques. This is one reason for my insistence on referring primarily to Maturana's work in defining enactivist concepts. Third, and finally, a source of incoherence is the lack of a generally agreed upon definition of a social system. There is no reason why a suitable definition cannot be found, and I suspect replacing Maturana's 'love' with something like a shared emotional orientation (Maturana 1988) would be sufficient, but this remains to be done. 


\section{References}

Barnes, J. M. 1994. Human-computer enaction, Unpublished doctoral dissertation. Edmonton, Alberta: University of Alberta.

Bateson, G. 2000. Steps to an ecology of mind. Chicago: University of Chicago Press.

Bateson, G. 1979. Mind and nature: A necessary unity. New York: Dutton.

Bateson, G. 1972. Steps to an ecology of mind: Collected essays in anthropology, psychiatry, evolution, and epistemology. Lanham, MD: Jason Aronson.

Bauersfeld, H. 1980. Hidden dimensions in the so-called reality of a mathematics classroom. Educational studies in mathematics, 11(1): 23-41.

Beer, S. 1980. Preface to Autopoiesis. H. Maturana \& F. Varela, eds. Autopoiesis and cognition: The realization of the living: 63-72. Dordecht: D. Reidel Publishing Co.

Begg, A. 2013. Interpreting enactivism for learning and teaching. Education sciences \& society, 4(1): 81-96.

Begg, A. 2002. Enactivism and some implications for education: A personal perspective. Vinculum, 39(2): 4-12.

Begg, A. 1999. Enactivism and mathematics education. In J. Truran \& K. Truran, eds. Making the difference: Proceedings of the twenty-second annual conference of the Mathematics Education Research Group of Australasia: 68-75. Adelaide, South Australia:MERGA.

Bernstein, B. 2000. Pedagogy, symbolic control and identity: Theory, research, critique. Revised edition. Lanham, MD: Rowman \& Littlefield.

Blackmore, D., Cluett, G. \& Reid, D. 1996. Three perspectives on problem-based mathematics learning. E. Jakubowski, D. Watkins, \& H. Biske, eds. Proceedings of the Eighteenth Annual Meeting of the North American Chapter of the International Group for the Psychology of Mathematics Education, Volume 1: 258-262. Columbus OH: ERIC Clearinghouse for Science Mathematics, and Environmental Education.

Bourgine, P. \& Stewart, J. 2004. Autopoiesis and cognition. Artificial life, 10(3): 327-345.

Brousseau, G. 1997. Theory of didactical situations in mathematics: Didactique des mathématiques, 1970-1990. Eds \& Trans. N. Balacheff, M. Cooper, R. Sutherland, \& V. Warfield. Dordrecht: Kluwer.

Brown, L. \& Coles, A. 2010. Mathematics teacher and mathematics teacher educator change: Insight through theoretical perspectives. Journal of mathematics teacher education, 13(5): 375-382.

Brown, L. \& Coles, A. 2008. Hearing silence: Steps to teaching mathematics. Cambridge UK: Black Apollo Press.

Brown, L. \& Coles, A. 2000. Complex decision making in the classroom: the teacher as an intuitive practitioner. T. Atkinson \& G. Claxton, eds. The intuitive practitioner: 
On the value of not always knowing what one is doing: 165-181. Buckingham, UK: Open University Press.

Brown, L. \& Coles, A. 1997. The story of Sarah: seeing the general in the particular? E. Pehkonen, ed. Proceedings of the twenty-first annual conference of the International Group for the Psychology of Mathematics Education, Volume 2: 113120. Lahti, Finland: PME 21.

Brown, L. \& Reid, D. 2006. Embodied cognition: Somatic markers, purposes and emotional orientations. Educational studies in mathematics, 63(2): 179-192.

Brown, L. \& Reid, D. 2004. Emotional orientations and somatic markers: Implications for mathematics education. M.J. Høines \& A.B. Fuglestad, eds. Proceedings of the Twenty-eighth conference of the International Group for the Psychology of Mathematics Education, Volume 1: 123-126. Bergen, Norway: PME

Brown, L. \& Reid, D. 2003. Observing the unseeable: Somatic markers related to students' and teachers' decision-making. Williams, J. ed. Proceedings of the British Society for Research into Learning Mathematics, 23(2): 19-24.

Brown, L. \& Reid, D. 2002. Somatic markers: Teachers' decision-making and students' emotioning in mathematics classrooms. Proceedings of the British Society for Research in the Learning of Mathematics, 22(3): 7-12.

Brown, L., Reid, D. A. \& Coles, A. 2003. Seeing patterns: Somatic markers in teachers' decision-making and students' reasoning in mathematics classrooms. Research in mathematics education, 5(1): 17-30. DOI:10.1080/14794800008520112

Campbell, S. \& Dawson, A. J. 1995. Learning as embodied action. R. Sutherland, \& J. Mason, eds. Exploiting mental imagery with computers in mathematics education: 233-249. Heidelberg: Springer.

Campbell, S. 2010. Embodied minds and dancing brains: New opportunities for research in mathematics education. B. Sriraman \& L. English (Eds), Theories of mathematics education. Seeking new frontiers: 309-331. Heidelberg: Springer.

Chevallard, Y. 1999. L'analyse de pratiques professorales dans la théorie anthropologique du didactique. Recherches en didactique des mathématiques, 19(2): 221-266.

Cobb, P. 1986. Contexts, goals, beliefs, and learning mathematics. For the learning of mathematics, 6(2): 2-9.

Cobb, P. 1985. Two children's anticipations, beliefs, and motivations. Educational studies in mathematics, 16(2): 111-126.

Coles, A. 2011. Metacommunication and Listening: An enactivist study of patterns of communication in classrooms and teacher meetings in one secondary mathematics department in the UK. Doctoral dissertation. Bristol UK: University of Bristol.

Confrey, J. 1992, February. How compatible are radical constructivism, social-cultural approaches and social constructivism? Paper presented at "Alternative Epistemologies in Education," Athens, Georgia. Source: https://gismodb.fi.ncsu.edu/files/resources/How_Compatible.pdf, 27.11.2013. 
Damasio, A. 1994. Descartes' error: Emotion, reason, and the human brain. New York: Avon Books/ G. P. Putnam's Sons.

Davis, A. B., Sumara, D. \& Kieren, T. 1996. Cognition, co-emergence, curriculum. Journal of curriculum studies, 28(2): 151-169.

Davis, B. \& Simmt, E. 2003. Understanding learning systems: Mathematics education and complexity science. Journal for research in mathematics education, 34(2): 137-167.

Davis, B. \& Sumara, D. 2006. Complexity and education: Inquiries into learning, teaching, and research. Mahwah, NJ: Lawrence Erlbaum Associates.

Davis, B. \& Sumara, D. 1997. Cognition, complexity, and teacher education. Harvard educational review, 67(1): 105-126.

Davis, B. 2004. Inventions of teaching: A genealogy. Mahwah, NJ: Lawrence Erlbaum.

Davis, B. 1997. Listening for differences: An evolving conception of mathematics teaching. Journal for research in mathematics education, 28(3): 355-376.

Davis, B. 1996. Teaching mathematics: Toward a sound alternative. New York: Garland Publishing.

Davis, B. 1995. Why teach mathematics? Mathematics education and enactivist theory. For the learning of mathematics, 15(2): 2-9.

Davis, B. 1994. Listening to reason: An inquiry into mathematics teaching. Unpublished doctoral dissertation. Edmonton, Alberta: University of Alberta.

Edwards, L. \& Núñez, R. (1995). Cognitive science and mathematics education: A nonobjectivist view. L. Meira \& D. Carraher, eds. Proceedings of the nineteenth annual conference of the International Group for the Psychology of Mathematics Education, Volume 2: 240-247. Recife: PME.

Ernest, P. 2010. Reflections on theories of learning. B. Sriraman \& L. English, eds. Theories of mathematics education. Seeking new frontiers: 39-47. Heidelberg: Springer.

Ferrara, F. 2003. Metaphors as vehicles of knowledge: An exploratory analysis. N. Pateman, B. Dougherty \& J. Zilliox, eds. Proceedings of the twenty-seventh annual conference of the International Group for the Psychology of Mathematics Education, Volume 2: 373-380. Honolulu, HI: PME.

Gordon Calvert, L. 1999. Mathematical conversations within the practice of mathematics. Unpublished doctoral dissertation. Edmonton, Alberta: University of Alberta.

Gordon Calvert, L., Kieren, T., Reid, D. \& Simmt, E. 1995. Thinking otherwise: Enactivism, mathematics and education. Paper presented at the meeting of the Canadian Society for the Study of Education, Montreal.

Hadamard, J. 1945. The mathematician's mind: The psychology of invention in the mathematical field. Princeton, NJ: Princeton University Press. 
Johnson, M. 1987. The body in the mind: The bodily basis of reason and imagination. Chicago: University of Chicago Press.

Kenny, V. 2007. Distinguishing Ernst von Glasersfeld's radical constructivism from Humberto Maturana's 'Radical Realism'. Constructivist foundations, 2(2-3): 5864 .

Kieran, C., Forman, E. \& Sfard, A. 2001. Guest Editorial: Learning discourse: Sociocultural approaches to research in mathematics education. Educational studies in mathematics, 46(1): 1-12.

Kieren, T. 1994. Orthogonal reflections on computer microworlds, constructivism, play and mathematical understanding. Journal of research in childhood education, 8(2): 132-141.

Kieren, T. \& Simmt, E. 2009. Response to Fazio and Gallagher: Brought forth in bringing forth. The inter-actions and products of a collective learning system. Complicity: An international journal of complexity and education, 6(2): 20-28.

Kieren, T., Gordon Calvert, L., Reid, D. \& Simmt, E. 1996. Occasioning: Learning in the interaction. Presented at the Annual Meeting of the American Educational Research Association, New York.

Kieren, T., Gordon Calvert, L., Reid, D. \& Simmt, E. 1995. An enactivist research approach to mathematical activity: Understanding, reasoning, and beliefs. Paper presented at the meeting of the American Educational Research Association, San Francisco.

Kilpatrick, J. 1992. A history of research in mathematics education. D. Grouws, ed. Handbook of research on mathematics teaching and learning: 3-38. New York: Simon \& Schuster Macmillan.

Konold, C. \& Johnson, D. 1991. Philosophical and psychological aspects of constructivism. In L. Steffe, ed. Epistemological foundations of mathematical experience: $1-13$. New York: Springer.

Krainer, K. 1993. Powerful tasks: A contribution to a high level of acting and reflecting in mathematics instruction. Educational studies in mathematics, 24(1): 65-93.

Lakatos, I. 1976. Proofs and Refutations. Princeton: Princeton University Press.

Lakoff, G. \& Núñez, R. 2000. Where mathematics comes from: How the embodied mind brings mathematics into being. New York: Basic Books,

Lakoff, G. 1987. Women, fire, and dangerous things: What categories reveal about the mind. Chicago: University of Chicago Press.

Lerman, S. 2010. Theories of mathematics education: Is plurality a problem? B. Sriraman \& L. English, eds. Theories of mathematics education. Seeking new frontiers: 99-109. Heidelberg: Springer.

Lerman, S. 1996. Intersubjectivity in mathematics learning: A challenge to the radical constructivist paradigm? Journal for research in mathematics education, 27(2): 133-150. 
Lozano, M-D. 2004. Characterising algebraic learning: An enactivist longitudinal study. Unpublished doctoral dissertation, University of Bristol.

Luhmann, N. 1997. Die Gesellschaft der Gesellschaft. Frankfurt am Main: Suhrkamp.

Luhmann, N. 1995. Social systems. Stanford: Stanford University Press.

Luhmann, N. 1986. The Autopoiesis of Social Systems. F. Geyer and J. Van d. Zeuwen, eds. Sociocybernetic paradoxes: Observation, control and evolution of self-steering systems: 172-192. London: Sage.

Mason, J. \& Johnston-Wilder, S., eds. 2004. Fundamental constructs in mathematics education. New York: RoutledgeFalmer.

Mason, R. 1997. Learning algebra personally. Unpublished doctoral dissertation. Edmonton, Alberta: University of Alberta.

Maturana, H. \& Poerksen, B. 2007. Autopoiesis and social theory: A conversation. Journal of sociocybernetics, 5(1-2): 68-73.

Maturana, H. \& Varela, F. 1987. The tree of knowledge: The biological roots of human understanding. Boston: New Science Library/Shambhala Publications.

Maturana, H. \& Varela, F. 1980. Autopoiesis and cognition: The realization of the living. Dordecht: D. Reidel Publishing Co.

Maturana, H. 2002. Autopoiesis, structural coupling and cognition: A history of these and other notions in the biology of cognition. Cybernetics \& human knowing, 9(34): 5-34.

Maturana, H. 1988. Reality: The search for objectivity or the quest for a compelling argument. The Irish journal of psychology, 9: 25-82.

Maturana, H. 1987. Everything said is said by an observer. W. Thompson, ed. Gaia: A way of knowing: 65-82. Hudson, NY: Lindisfarne Press.

Maturana, H. 1980b. Man and society. F. Benseler, P. Hejl \& W. Köck, eds. Autopoiesis, communication, and society: The theory of autopoietic systems in the social sciences: 11-32. Frankfurt: Campus Verlag.

Maturana, H. 1980a. Biology of cognition. H. Maturana \& F. Varela, eds. Autopoiesis and cognition: The realization of the living: 5-58. Dordecht: D. Reidel Publishing Co.

Maturana, H. 1978b. Cognition. P. Hejl, W. Köck \& G. Roth, eds. Wahrnehmung und Kommunikation: 29-49. Frankfurt: Peter Lang.

Maturana, H. 1978a. Biology of language: The epistemology of reality. G. Miller \& E. Lenneberg eds. Psychology and biology of language and thought: Essays in honor of Eric Lenneberg: 27-63. New York: Academic Press.

Maturana, H. 1975. The organization of the living: A theory of the living organization, International Journal of Man-Machine Studies, 7: 313-332.

Nicol, C. \& Lerman, S. with assistance from Joop van Dormolen, Carolyn Kieran, Gerard Vergnaud, Kath Hart and Heinrich Bauersfeld. 2008. A brief history of the International Group for the Psychology of Mathematics Education (PME) Source: http://www.icmihistory.unito.it/pme.php, 29.11.2013. 
Núñez, R. \& Edwards, L. 1995. Embodied cognition and the psychology of mathematics education: A discussion gorup. L. Meira \& D. Carraher, eds. Proceedings of the nineteenth annual conference of the International Group for the Psychology of Mathematics Education, Volume 1: 184. Recife: PME.

Núñez, R., Edwards, L. \& Matos, J. (1999). Embodied cognition as grounding for situatedness and context in mathematics education. Educational studies in mathematics, 39(1-3): 45-65.

Oehrtman, M. C. 2003. Strong and weak metaphors for limits.B. Dougherty \& J. Zilliox, eds. Proceedings of the twenty-seventh annual conference of the International Group for the Psychology of Mathematics Education, Volume 3: 397-404. Honolulu, HI: PME.

Pirie, S. \& Kieren, T. 1989. A recursive theory of mathematical understanding. For the learning of mathematics, 9(3): 7-11.

Poincaré, H. 1914. Science and method. DoverPublications.com.

Radford, L., Edwards, L. \& Arzarello, F. 2009. Introduction: beyond words. Educational studies in mathematics, 70(2): 91-95.

Reid, D. \& Brown, L. 1999. Fork in the road. For the learning of mathematics, 19(3): 1522.

Reid, D. \& Drodge, E. 2000. Embodied cognition and the mathematical emotional orientation. Mathematical thinking and learning, 2(4): 249-267.

Reid, D. 2002b. Elements in accepting an explanation. Journal of mathematical behavior, 20(4): 527-547.

Reid, D. 2002a. Conjectures and refutations in grade 5 mathematics. Journal for research in mathematics education, 33(1): 5-29

Reid, D. 1999. Needing to explain: The mathematical emotional orientation. Orit Zaslavsky. ed. Proceedings of the twentieth-third annual conference of the International Group for the Psychology of Mathematics Education, Volume 4: 105112. Haifa, Israel: PME.

Reid, D. 1996. Enactivism as a methodology. L. Puig \& A Gutiérrez, eds. Proceedings of the twentieth annual conference of the International Group for the Psychology of Mathematics Education, Volume 4: 203-210. Valencia, Spain: PME.

Reid, D. 1995. The need to prove. Unpublished doctoral dissertation. Edmonton, Alberta: University of Alberta.

Reid, D., Brown, L. \& Coles, A. 2001. Observing systems. Working session at the twentieth-fifth annual conference of the International Group for the Psychology of Mathematics Education, Utrecht, July 2001.

Ruthven, K., Laborde, C., Leach, J. \& Tiberghien, A. 2009. Design tools in didactical research: Instrumenting the epistemological and cognitive aspects of the design of teaching sequences. Educational researcher, 38(5): 329-342. 
Samson, D. \& Schäfer, M. 2010. Beyond constructivism: Enactivism as a theoretical lens in the context of figural pattern generalisation. V. Mudaly, ed. Proceedings of the eighteenth annual meeting of the Southern African Association for Research in Mathematics, Science and Technology Education (SAARMSTE), Book of Abstracts: 21. Durban, SA: University of Kwazulu-Natal.

Samson, D. \& Schäfer, M. 2011. Figural apprehension, enactivism and knowledge objectification: An exploration of figural pattern generalisation. For the learning of mathematics, 31(1): 37-43.

Samson, D. \& Schafer, M. 2012. The case for manipulatives: Enabling "ways of seeing”. In D. Nampota \& N. Kazima, eds. Proceedings of the twentieth annual meeting of the Southern African Association for Research in Mathematics, Science and Technology Education (SAARMSTE), Volume 1: Long Papers: 220-232. Lilongwe, Malawi: SAARMSTE.

Simmt, E. 2000. Mathematics knowing in action: A fully embodied interpretation. Unpublished doctoral dissertation. Edmonton, Alberta: University of Alberta.

Simon, M. A. 2013. The need for theories of conceptual learning and teaching of mathematics. K. Leatham, ed. Vital directions for mathematics education research: 95-118. New York: Springer.

Skemp, R. 1971. The psychology of learning mathematics. Baltimore, MD: Penguin Books.

Sriraman, B. \& English, L. (Eds). 2010. Theories of mathematics education. Seeking new frontiers. Heidelberg: Springer.

Steinbring, H. 2005. Analyzing mathematical teaching-learning situations: The interplay of communicational and epistemological constraints. Educational studies in mathematics, 59(1-3): 313-324.

Steinbring, H. 1999. Mathematical interaction as an autopoietic system: Social and epistemological interrelations. I. Schwank, ed. European Research in Mathematics Education, Proceedings of the First Conference of the European Society for Research in Mathematics Education Volume 1-2: 387-400. Osnabrück: Forschungsinstitut für Mathematikdidaktik.

Thompson, P. 2008. Conceptual analysis of mathematical ideas: Some spadework at the foundation of mathematics education. O. Figueras, J. L. Cortina, S. Alatorre, T. Rojano \& A. Sépulveda, eds. Proceedings of the Thirty-second annual meeting of the International Group for the Psychology of Mathematics Education, Volume 1: 45-64. Morélia, Mexico: PME.

Varela, F. (1981). Autonomy and autopoiesis. In G. Roth, \& H. Schwegler, eds. Selforganizing systems: an interdisciplinary approach:14-24. New York: Campus Verlag.

Varela, F., Thompson, E. \& Rosch, E. 1991. The embodied mind: Cognitive science and human experience. Cambridge MA: MIT Press.

von Glasersfeld, E. 1991. Distinguishing the observer: An attempt at interpreting Maturana. Methodologia, V (8): 57-68 
von Glasersfeld, E. 1989. Cognition, construction of knowledge, and teaching. Synthese, 80(1): 121-140.

Wertsch, J. 1985. Vygotsky and the social formation of mind. Cambridge MA: Harvard University Press.

Zeleny, M. \& Hufford, K. 1991. All autopoietic systems must be social systems (living implies autopoietic. But, autopoietic does not imply living): An application of autopoietic criteria in systems analysis. Journal of social and biological structures, 14(3): 311-332. 